\title{
Academic integrity in Ukrainian higher education: values, skills, actions
}

\section{Artem Artyukhov}

Ph.D., Associate Professor, Head of Centre of Scientific \& Technical and Economical Information of Sumy State University, Coordinator of Strengthening Academic Integrity in Ukraine Project in Sumy State University, Head of Subcommittee "Academic Integrity" (Ministry of Education and Science of Ukraine), Ukraine.

\section{Olga Liuta}

Ph.D., Associate Professor, Sumy State University, Sumy, Ukraine.

(C) The Authors, 2017. This article is published with open access at ARMG Publishing.

\begin{abstract}
The article is devoted to the main challenges facing the student community and teaching staff towards building a European-style university with getting the principles of academic integrity. The basic universal norms, which should enter into the daily life of the university and ensure the improvement of the quality of educational and scientific process, are shown. The basic manifestations of academic dishonesty are presented. Based on the own experience of the authors the method of active implementation of the principles of academic integrity in the lives of students and teacher activities are show. The main objective of the further work is to create a culture for communities, which believe that honesty and integrity are fundamental values that define how we teach and learn.
\end{abstract}

Keywords: academic integrity, plagiarism, academic fraud, applicants of higher education.

JEL Classification: A22, A29.

\section{Introduction}

Today the quality of higher education is impossible without respect the principles of academic integrity, providing a set of values in learning, teaching, scientific research. In modern conditions the observance of academic integrity provides for educational institutions competitive advantages in the educational market, positioning it as the responsible subject in this field. Throughout the civilized world, academic integrity and attitudes in the university is also an important factor for international cooperation and the formation of trust from foreign partners.

In higher education institutions, observance of the foundations of academic honesty should become a composite institutional policy, the implementation of which is ensured by understanding the educational process by each participant the need to introduce a new paradigm and the principle of academic cooperation. Observance of academic honesty in the domestic educational space should be the indicator that characterizes real changes in the academic culture of our country.

\section{Literature review}

To date, the issue of academic honesty as an ethical component of modern science is actively discussed both by representatives of the national and world academic community. The authors note that in the current conditions of educational space functioning, it is precisely the principle of academic integrity that should be the basis for the activities of the modern university [6]. An important aspect in the development of academic integrity in the Ukrainian higher education institutions is the study of European practice and American universities practices. This is the subject of the works of such scientists as V. Romakin, who describes the motivation and beliefs of Ukrainian and American students in terms of academic honesty [11]; O. Tsokur, who emphasizes the need to introduce an academic service that deals with the issues of the "code of honesty" as implemented in the US higher education system [14]. Considerable attention is paid to the problem of plagiarism, as the most common form of academic fraud. Thus, V.V. Pobizhenko, I.A. Pobizhenko note today plagiarism is one of the factors of the decline in the quality of higher education in Ukraine [9]. Unethical behavior is often characterized by an academic is the student body in the performance of tasks or exams as noted V.I. 
Shinkarenko [12]. However, despite a significant number of publications in this area, the problem of identifying areas for overcoming the manifestations of academic dishonesty in higher educational institutions of Ukraine remains urgent.

\section{Methods}

The methodological basis of the research is modern concepts of providing academic honesty, scientific works of domestic and foreign authors devoted to the problems of academic virtue in higher educational institutions. In the process of research, such modern methods as: analysis, synthesis and scientific abstraction (with the specification of the category "academic honesty"), comparative and statistical analysis, the method of logical generalization (in researching the provision of academic honesty in higher educational institutions of Ukraine) were used.

Information-factual base of the research was collected, processed and summarized by the authors which is represented by materials regarding approaches to ensure academic integrity in Ukraine and the world, official data of the Ministry of Education and Science of Ukraine, legislative and regulatory acts, report data of the Institute of Educational Analytics, monographic research and scientific publications on academic honesty.

\section{Results}

\section{The essence and principles of academic integrity}

In the current state of development of Ukrainian university education, the principles of academic honesty are either perceived as abstract, fashionable, often recalled in words, but not used in practice, or, at best, as a reason to prohibit students and teachers to use uncontrollably and irresponsibly others' thoughts, issuing them for their own, and determine the order of punishment for plagiarism and copying. In this sense, academic honesty comes down to the rules of working with information. This understanding of the problem is too narrow, since the essence of its solution lies primarily in the worldview-value plane.

In the world practice, the notion of "academic integrity" is used to determine honesty in teaching.

Nowadays, the phrase "academic honesty" is quite new, which, in turn, leads to different approaches to its interpretation.

In domestic explanatory dictionaries, "academic" refers to everything that is associated with a high level in the field of science, and also apply it as a synonym for the term "educational". Western scientific thought treats the concept of "academic" as: 1) scientific; 2) what has to do with school, college, university; 3 ) what has more theoretical interest than practical value.

The term "integrity" derives from the late Latin words "integer" (integer), integrare (integer) or "integritas" (integrity). In the modern sense, the notion of "integrity" means "moral purity", "decency", "integrity", completeness [1].

It should be noted that until recently the notion of "academic honesty" was not reflected in domestic regulatory and legislative acts. For the first time the term "academic integrity" is mentioned in the Law of Ukraine "On Higher Education" as a component of the internal quality assurance system.

The definition of this concept is given in Article 36 of the draft Law of Ukraine "On Education", where it is indicated. It is a combination of ethical principles and statutory rules that should guide participants in the educational process during teaching, and conducting scientific (creative) activities to ensure trust in learning outcomes and/or scientific (creative) achievements.

It should be mentioned that in the establishment of the principles of academic integrity it is quite a complicated process that involves not only the definition, fixation, but also the conscious and free adoption of these principles by all members of the academic community. The presence of goodwill, enlighte nment of enthusiasm, confidence in one's rightness among adherents of academic virtue, combined with modern information technologies allow to accelerate this process in time and expand the circle of ideological supporters of these principles.

Public acceptance of the principles of academic integrity should be an example of a positive change in public consciousness and an important step in systematic introduction of high standards of educational and research activities in Ukraine's educational institutions [1]. 
Each organization uses a certain set of universal norms, often expanding its positions, originating from its own experience. Using the publication of the Council of Europe on the "Moral behavior of the participants in the educational process" [8], the authors successfully combined the ideas of many international documents, somehow defined the concept of ethical principles in higher education.

Virtue - continuous devotion of individuals and all institutions to moral principles and standards that create a barrier to dishonesty.

Honesty is the systematic avoidance of fraud, deception, theft and any dishonest behavior.

The truth is an unlimited desire for truth, free and open dissemination of knowledge and their improvement (enrichment).

Transparency is the accessibility and openness of information, rules, plans, processes and actions that required that university employees to act openly, predictably and understandably, promote their own accountability and the involvement of participants in the educational process.

Respect for others - respect for the dignity of others, their physical and mental health, for the benefit of collegiality and cooperation with other participants in the educational process.

Trust - all participants in the educational process have confidence in the integrity and can rely on each other.

Accountability - participants in the educational process use the delegated authority properly.

Equity is an impartial, equal attitude to all participants in the educational process, free of discrimination and dishonesty.

Equality and social justice - equal access to education irrespective of race, color, political, religious or other convictions, gender, gender identity, sexual orientation, ethnic, social, national origin, health status, disability.

Democratic governance - the management of the higher education system and the university should be based on the involvement of all relevant participants in the educational process and ethical performance of their powers by the leadership at different levels.

Quality education - all participants are committed to achieving the highest possible quality of education.

Self-improvement and improvement of the system - the participants in the educational process recognize the importance and make the utmost efforts to improve the educational system continuously, in particular through their own professional growth.

Institutional autonomy is the recognition of the need for appropriate autonomy of universities in order to avoid excessive centralized political control over the educational system.

International cooperation - all participants of the educational process recognize the importance of an international collaboration in education.

\section{Classification and causes of academic malpractice}

The phenomenon of academic inferiority is multifaceted and can take various forms. It is based on intentional violation of the generally accepted moral and legal norms in the academic environment, usually with a view to obtain certain advantages. In any case, the prevalence of such manifestations strikes a crushing blow to the quality of education and the quality of scientific research, turning them into opposite phenomena - graduated pseudo-education and dangerous pseudoscience.

The manifestations of academic inferiority can be divided into two groups:

$>$ negligence in educational activities;

unkindness in scientific activity.

However, such a division is rather arbitrary, because in modern conditions educational activity is inextricably linked with the scientific. Below we try to give the main forms of manifestations of academic malpractice [10].

The most common manifestation of academic misconduct is undoubtedly plagiarism, that is, the deliberate or deliberate publication (publication) in whole or in part of someone else's work (text or ideas) under the name of a person who is not the author of this work, without proper reference. Plagiarism can take place both in the performance of educational tasks and in scientific activity. Sometimes a phenomenon like 
self-plagiarism or "recycling fraud" happens, which involves using the author's own previous works in a different context, without reference to the fact that such text has already been used or published.

The writing off of answers from another person when drawing up any type of final or current control (exam, test, etc.) is a manifestation of dishonesty, which relates mainly to the educational process.

Acquisition from other persons or organizations with a subsequent presentation of results of educational and scientific activity (reports, abstracts, control, calculation, course, diploma and master's works, essays, articles, monographs, teaching aids, etc.) is definitely one of the most common manifestations of disfavour next to plagiarism.

A whole group of manifestations of academic unkindness can be called academic fraud, cheating, which can take the following forms:

garble, falsification of bibliography items usually manifests itself in the form of a reference to the history, were not used in the work;

$>$ manipulation, falsification of the results of scientific research, that is, representations of empirical data that differ from those actually received to confirm their own theoretical constructs.

Simulation the deterioration of health, disease, in order to avoid control measures is a manifestation of illwill, which is often backed up by fictitious medical certificates obtained illegally.

With the development of information technology, the miniaturization of electronic devices, such a widespread manifestation of dishonesty as the use of forbidden auxiliary materials (cribs, abstracts, etc.) during the control activities (exam, test, test work, etc.) is gradually changing to use during prohibited activities of prohibited technical means (micro-headphones, telephones, smartphones, tablets, etc.).

Fraud also includes forgery of signatures in official documents (credit books, acts, reports, agreements, etc.).

There are other ways of academic fraud, which are common among people receiving education, namely: the passage of procedures for monitoring knowledge by front men, delivery or representation by different persons of works with the same content as a result of educational or scientific activity; writing another variants of tasks on control measures; the use of a system of hidden signals (sound, gestures, etc.) in the performance of group control activities, tests, etc., with the same options, obtaining unauthorized assistance in the performance of tasks that require independent implementation.

Fabrication of data or results, which is the receipt or publication of research results, without conducting the research by itself (experiment, measurements, etc.), is most often characterized in the implementation of scientific (read-pseudo-scientific) activities.

The existence of separate norms and requirements on the compulsory evaluation of scientific works by the representatives of scientific community causes such a form of disapproval as the provision of reviews or reviews of scientific or educational work without proper examination.

Unfair competition between persons, receiving education, or between scientists sometimes leads to such a phenomenon as damage, spoiling, sabotage of educational or research work of others (corruption, destruction of digital files, paper materials, etc.).

The imitation of scientific and educational activities is often associated with such a manifestation of dishonesty as inclusion in the list of authors of scientific, educational or project executors of persons who did not take part in the preparation (writing) and obtaining scientific results. Often such actions become a "generally accepted tradition" in domestic universities and academic institutions, when the list of performers "automatically" includes the heads of scientific and educational institutions, units, heads of graduation papers, master's and doctoral dissertations.

Considering such a manifestation as the receipt or offer improper remuneration for unfair receiving benefits in training, research or employment (corruption, bribery), it should be noted, that it can be characterized at any level of functioning of educational and scientific system of corruption at the highest level at allocation of budget funding to the "normal" paid for obtaining estimates for tests, exams. The use of related or employment relationships for the positive or the highest rating in the preparation of any type of final control or advantages in scientific work should be included by the manifestations of this kind.

Crime has a shade and a form malpractice how to use blackmail or bribery in educational and scientific activities. 
Some of the above manifestations of academic malpractice can be combined in a group called "unauthorized collaboration", which includes the provision of assistance to commit an act of academic dishonesty - deliberate or conscious attempt to help or aid another to commit an act of academic dishonesty.

Among other manifestations of academic malpractice note the following.

Forced donations and forced labor. Forcing students to pay money or perform some work under the threat of deliberate harm the interests and rights of a student in school, at home, or other issues.

Conflict of interest. Actual and potential conflicts between personal property, non-property interests of the person or persons close to him and its powers, whose presence could affect the objectivity and impartiality of the decision-making, as well as to do or abstain from action during the execution of the powers granted to it. In the case of potential conflicts we are talking about cases where the defendant did not warn people, depending on the result of the decision in advance about the existence of such a conflict.

Nepotism and the abuse of power. The use of family ties or official position to gain an advantage in academic, extracurricular, scientific or administrative field.

As a result, we note that the concealment or covering actions that could be construed as an academic malpractice in it is a manifestation of the academic malpractice.

In our opinion, the main reasons of academic malpractice in the national high school is as follows:

$>$ systemic phenomenon of academic malpractice and inefficient system to combat academic dishonesty at the state level, discouraging the academic community;

$>$ uncertainty sanctions for academic dishonesty both at the state level and at the level of higher education institutions;

$>$ a large load of students and teachers, in which students do not have opportunities to perform tasks qualitatively and teacher check it [11];

$>$ lack of motivation in students for writing original works [3];

$>$ absence of curriculum disciplines provide students with practical skills of writing scientific papers;

$>$ teaching experience in middle school where cheating is the norm of conduct for the majority of students [11];

$>$ low motivation for knowledge for many students when determining factor is the degree of training, rather than high-quality knowledge.

$>$ low ethical standards when cheating is not recognized as a crime;

$>$ the members of the academic community does not have a standard of academic conduct, as well as the boundaries of unacceptable academic behavior.

\section{Directions to overcome academic malpractice}

The experience of developed countries shows that in the vast majority of universities, considerable attention is paid to the fight against academic dishonesty through the creation, of certain rules and regulations for students and teachers who have to form the code of honor, a written oath to the lack of academic delusion, the Guidelines for the avoidance of plagiarism for students, guide for teachers to combat student plagiarism.

In Ukraine a small portion of higher educational institutions has developed and effective action to prevent the academic system of malpractice. According to a survey conducted in 2016 by the Institute of educational analysts, where 172 universities took part in the study, only $27(15.5 \%)$ institutions have codes of honor student or its analogs, and 19 high schools $(11 \%)$ - codes of ethics of the teacher or similar documents. Only in 26 institutions of higher education the position counter plagiarism or documents that specify the relevant principles are in the public domain [2].

In our opinion, the basic areas of work in higher education institutions for the prevention of manifestations of academic malpractice should be considered in two ways: on the university level and at the level of teachers.

A policy counter academic malpractice at the university level should include, first of all, the development of effective conservation and protection intellectual property of university, and participants of educational and scientific processes, respect copyright and avoid academic plagiarism in all kinds of scientific and educational activities.

The work of teaching staff with students is the implementation of the following measures:

the introduction of mandatory testing of all types of work with the help of programs Etxt.ru; Advego Plagiatus and Anti-Plagiarism [12]; 
use of programs to analyze the foreign language texts close on subjects;

development of control tasks based on real situations and the implementation of which requires the citation, and the analysis and synthesis of the material studied;

$>$ while organization of independent work of students it is advisable to offer tasks allowing students not to compile materials and think independently, summarize and analyze the material.

\section{Conclusions and discussion}

Implementation of the principles of academic integrity needs a fundamental restructuring of organization of educational activities in national universities, the introduction of new rules of behavior and monitoring their compliance, formation of social rejection manifestations of academic fraud. Systemic work in this area should lead to the transformation of academic culture and adoption of high-grade foundations of academic virtues in domestic universities.

\section{References}

1. Finikov T., A. Artyukhov A. (2016). Academic integrity as the basis for sustainable development of the university / Kyiv, Taxon, p. 234.

2. Analytical Reference on the results of investigations of practices of academic integrity in higher education institutions (2016) Resource document. Ministry of Education and Science. Retrieved from: http://mon.gov.ua/content/\%D0\%9D\%D0\%BE\%D0\%B2\%D0\%B8\%D0\%BD\%D0\%B8/2016/08/09 /academichna-dobrochesnist.pdf. Accessed 6 March 2017.

2. Efimova, G. (2011). Analisys of reasons of academic cheating and their classification. Retrieved from: http://naukovedenie.ru/PDF/24pvn412.pdf. Accessed 6 March 2017.

3. Ethical problems of science at the beginning of the XXI century (2015). Retrieved from: https://allendy.ru/filnauki/456-etika-nauki.html. Accessed 4 March 2017.

4. Zazirniy, I., Kostrub, O. (2016). Plagiarism: What is it and how we understand it in Europe? Injury, 1, 125-126.

5. Sharshekeeva, Kamilla D. (2000). The principle of academic honesty as the basis of activity of modern university. Retrieved from: http://elibrary.auca.kg:8080/dspace/bitstream/123456789/141/1/ Sharshekeeva_Printsip\%20akademicheskoi\%20chestnosti.pdf. Accessed 4 March 2017.

6. Kalinovskiy, Yu. (2011). Academic honesty as a factor in the legal education of students. Retrieved from: http://dspace.nulau.edu.ua/bitstream/123456789/2201/1/Kalinovsky_477-482.pdf,

7. Pan-European Platform on Ethics, Transparency and Integrity in Education (ETINED). Ethical behavior of all actors in education $/ 7^{\text {th }}$ Prague Forum Towards a Pan-European Platform on Ethics, Transparency and Integrity in Education Charles University, Prague, Czech Republic 1-2 October 2015. 58 p.

8. Pobizhenko, V., Pobizhenko, I. (2011). Plagiarism as a factor of the quality of education reducing. Information Processing Systems, 8, 310-313.

9. Recommendations for ensuring academic integrity principles (2017). Ministry of Education and Science of Ukraine, Scientific-methodical commission of organizational and methodological support of higher education, Subcommittee "Academic Integrity". 2017. 24 p.

10. Romakin, V. (2002). Academic honesty in higher education. Retrieved from: http://lib.chdu. edu.ua/pdf/naukpraci/pedagogika/2002/20-7-3.pdf Accessed 5 March 2017.

11. Shynkarenko, V. (2012). The control plagiarism in student papers. East Europe Journal of Advanced Technologies, 4(2), 32-36.

12. Singayivska, A. (2013). Plagiarism as a mirror of higher education. Herald of the National Technical University of Ukraine. Series: Philosophy. Psychology. Pedagogy, 2, 41-42.

13. Tsokur, O. (2009). "Code of Honor" in US higher education. Vestnik of Cherkassky National University of Bohdan Khmelnytsky. Series: Teaching Science, 150, 57-62. 